\title{
Green Marketing dan Quality Brand Sebagai Prediktor Perilaku Konsumen dan Dampaknya Terhadap Keputusan Pembelian Produk
}

by

\author{
Putu Agus Indra Purnama (1) \\ Nyoman Rasmen Adi ${ }^{(2)}$ \\ PT. Guna Putra Engineering ${ }^{(1)}$ \\ Universitas Pendidikan Nasional (2) \\ putuagus_indrapurnama@ymail.com ${ }^{(1)}$ \\ rasmenadi1958@gmail.com ${ }^{(2)}$
}

\begin{abstract}
The research objective was to find out to determine the effect of green marketing on consumer behavior, influence of brand quality on consumer behavior, influence of brand quality on purchasing decisions, influence of green marketing on purchasing decisions, influence of consumer behavior on purchasing decisions, consumer behavior on the influence of green marketing on decisions purchase, knowing the mediation of consumer behavior on the effect of green marketing on purchasing decisions, knowing the mediation of consumer behavior on the influence of quality brands on purchasing decisions Data collection using semantic difference scale questionnaire. The research method used purposive sampling and accidental sampling using 140 people. Analysis method using SPSS 22. Using AMOS computer application version 22. The results of this study show that green marketing and quality brands have a positive and significant effect on consumer behavior, consumer behavior and brand quality have a positive and significant effect on purchasing decisions, green marketing has a non-significant positive influence on purchasing decisions, consumer behavior can mediate the influence of green marketing and brand quality on decisions purchase at nike.
\end{abstract}

\section{Keywords: Green Marketing, Quality Brand, Consumer Behavior, Decisions Purchase,} Nike 


\begin{abstract}
ABSTRAK
Tujuan penelitian adalah untuk mengetahui Untuk mengetahui pengaruh green marketing terhadap perilaku konsumen, pengaruh quality brand terhadap perilaku konsumen, pengaruh quality brand terhadap keputusan pembelian, pengaruh green marketing terhadap keputusan pembelian, pengaruh perilaku konsumen terhadap keputusan pembelian, perilaku konsumen pada pengaruh green marketing terhadap keputusan pembelian, mengetahui mediasi perilaku konsumen pada pengaruh green marketing terhadap keputusan pembelian, mengetahui mediasi perilaku konsumen pada pengaruh quality brand terhadap keputusan pembelian. Pengumpulan data menggunakan kuesioner skala semantic difference. Metode penelitian menggunakan purposive sampling dan accidental sampling menggunakan 140 orang. Metode analysis menggunakan SPSS 22. Menggunakan aplikasi komputer AMOS versi 22. Hasil penelitian ini menunjukan green marketing dan quality brand berpengaruh positif dan signifikan terhadap perilaku konsumen, perilaku konsumen dan quality brand berpengaruh positif dan signifikan terhadap keputusan pembelian, green marketing memiliki pengaruh positif yang tidak signifikan terhadap keputusan pembelian, perilaku konsumen mampu memediasi pengaruh green marketing dan quality brand terhadap keputusan pembelian di nike.
\end{abstract}

Kata kunci: Green Marketing, Quality Brand, Perilaku Konsumen, Keputusan Pembelian, Nike 


\section{PENDAHULUAN}

Perkembangan fashion pada era modern ini semakin beranekaragam, mulai dari ujung kepala sampai ujung kaki semuanya membutuhkan fashion yang menarik sebagai tanda bahwa mereka memiliki gaya hidup yang sesuai dengan perkembangan zaman modern. Kebutuhan fashion pada dasarnya merupakan sebuah kebutuhan primer bagi seorang individu karena fashion termasuk kebutuhan sandang dalam bagian kebutuhan primer (Darma, 2018). Bagi sebagian masyarakat modern kini perkembangan dunia fashion menjadikan sebuah gaya hidup baru bagi mereka, fashion seperti baju, celana, sampai sepatu berbagai merk yang selalu mengeluarkan model terbaru bagi produk mereka berdampak pada daya beli masyarakat yang terus meningkat untuk memenuhi gaya hidup mereka.

Sepatu merupakan salah satu fashion yang paling digemari beberapa waktu ini termasuk sepatu sport atau olahraga yang kini menjadi fashion bagi sebagian besar kalangan muda yang digunakan tidak hanya pada saat olahraga saja, akan tetapi juga dalam kegiatan sehari-hari seperti kuliah, traveling, dan kegiatan lainnya. Hal ini menjadikan dua produsen sepatu sport seperti nike, dan adidas saling bersaing untuk mendapatkan pasar agar produk mereka dapat diminati oleh konsumen. Teknologi Flyknit yang diluncurin pertama kali oleh Nike tahun 2012 terbukti mengubah peta persaingan di dunia sneakers dan sepatu olahraga. Tidak hanya ringan dan nyaman digunakan, Flyknit membawa dampak positif jangka panjang bagi lingkungan lewat penggunaan $100 \%$ bahan plastik daur ulang.

Dengan berbagai macam strategi marketing yang dijalakan oleh Nike demi terus menaikan penjualan tahun ke tahun Nike pun percaya akan sains, dan mengenai perubahan iklim adalah sesuatu yang nyata terjadi. Pemasaran produk yang menggunakan bahan-bahan yang tidak merusak lingkungan hidup sekarang ini dikenal dengan produk hijau (green product). Langkah-langkah pemasaran hijau yang sudah dilakukan oleh banyak produsen pada dasarnya direspon secara positif oleh konsumen bahwa dengan memperhatikan proses pemasaran produk dan jasa yang memiliki karakteristik aman bagi lingkungan serta meningkatkan kualitas produk akan membantu konsumen dalam mengambil suatu keputusan dimana quality brand yang ditawarkan sesuai dengan apa yang diharapkan oleh konsumen akan produk tersebut dapat menjadi faktor penting dalam mengambil keputusan dalam pembelian.Kualitas dan perilaku konsumen juga dibutuhkan oleh konsumen sebelum melakukan keputusan pembelian. Fakta membuktikan meskipun para konsumen menunujukan sikap (attitude) yang positif terhadap isu lingkungan, mereka pada saat yang bersamaan juga 
tidak melakukan tindakan pembelian pada produk-produk ramah lingkungan (Grupta dan Ogden 2009:377); (Ginantra dkk, 2017) dapat dikatakan meskipun konsumen memiliki tingkat kesadaran terhadap lingkungan, belum tentu akan membeli produk ramah lingkungan.

Proses pengambilan keputusan konsumen merupakan suatu bagian yang harus diperhatikan oleh para pelaku pasar, sebab dengan adanya pemahaman mengenai keputusan konsumen, maka pemasar suatu perusahaan akan lebih mudah dalam membuat suatu perencanaan pemasaran serta penetapan kebijakan pemasaran dan sebagai dasar dalam pelaksanaan kegiatan pemasara. Secara khusus di sector sepatu olahraga, perkembangan industry di bidang ini mengalami kenaikan. Volume penjualan sepatu dapat dilihat pada tabel.

Tabel 1.1

Volume Penjualan Sepatu Nike dan Adidas

\begin{tabular}{|l|l|l|}
\hline TAHUN & TAHUN 2016 & TAHUN 2017 \\
\hline NIKE & 268,650 triliun & 284,850 triliun \\
\hline ADIDAS & 188,450 triliun & 201,150 triliun \\
\hline
\end{tabular}

Sumber : Kumparan,Bisnis, 2017

Berdasarkan Tabel 1.1 Pada tahun 2016 volume penjualan sepatu Nike hampir dua kali lipat volume penjualan sepatu adidas dan pada tahun 2017 volume penjualan sepatu Nike hampir satu setengah kali lipat dari volume penjualan sepatu Adidas. Nilai kenaikan volume penjualan sepatu Nike lebih tinggi dibandingkan volume penjualan sepatu Adidas. Ini artinya Nike telah menguasai pasar sepatu sport dan sneakers. Ini menunjukan bahwa kemampuan marketing Nike lebih baik dari Adidas. Dengan demikian maka dipandang relevan diadakan kajian Green Marketing dan Quality Brand sebagai Prediktor Perilaku Konsumen dan dampaknya terhadap Keputusan Pembelian Produk Nike di Kota Denpasar.

\section{TINJAUAN PUSTAKA}

\section{Green Marketing}

Kusnadi dan Darma (2018) menyimpulkan bahwa Green Marketing yang jika diterjemahkan ke dalam bahasa Indonesia menjadi "Pemasaran Hijau", merupakan salah satu konsep pemasaran etis yang sebenarnya sudah cukup lama berkembang. Pemasaran hijau menggunakan isu-tentang lingkungan sebagai strategi untuk memasarkan produk. Green Marketing di dalam perusahaan memiliki beberapa proses seperti proses produksi, 
proses penentuan harga, proses promosi, dan proses distribusi produk (Setyawati dan Darma, 2018).

Green Marketing merupakan aktivitas yang luas, termasuk didalamnya adalah memodifikasi produk, perubahan proses produksi, perubahan pada kemasan produk, hingga perubahan pada periklanan produk tersebut. Green marketing merupakan salah satu kasus khusus dalam implementasi SCM, yang terinspirasi dari sikap dan perilaku baik konsumennya maupun produsennya. Green marketing merujuk pada kepuasan kebutuhan, keinginan dan hasrat pelanggan dalam hubungan pemeliharaan dan pelestarian dari lingkungan hidup. (Kembaren, 2009; Kusnadi dan Darma, 2018)

\section{Quality Brand}

Para peminat beli pelanggan potensial menginginkan agar produk harus dibuat berkualitas, terutama dalam memenuhi harapan konsumen agar menjadi puas dan loyal pada perusahaan. Wiandari dan Darma (2017) mengemukakan bahwa: Quality brand adalah kemampuan suatu produk untuk melaksanakan fungsinya, meliputi kehandalan, daya tahan, ketepatan, kemudahan operasi, dan perbaikan produk, serta atribut bernilai lainnya. Sedangkan menurut Armstrong dan Kotler (2007:206) Quality brand adalah: "Kemampuan produk untuk melaksanakan fungsi-fungsinya, kemampuan itu meliputi daya tahan, kehandalan, ketelitian yang dihasilkan, kemudahan dioperasikan dan diperbaiki dan atribut lain yang berharga pada produk secara keseluruhan”. Setiap perusahaan yang menginginkan dapat memenuhi kebutuhan dan keinginan pelanggan, maka akan berusaha membuat produk yang berkualitas, yang ditampilkan baik melalui ciri-ciri luar (design) produk maupun inti (core) produk itu sendiri.

\section{Perilaku Konsumen}

Menurut Handika dkk, 2018 menyatakan bahwa perilaku konsumen menggambarkan cara individu mengambil keputusan untuk memanfaatkan sumber daya mereka yang tersedia (waktu, uang, usaha) guna membeli barang-barang yang berhubungan dengan konsumsi. Ahli lain, Kotler dan Keller (2009:166) perilaku konsumen adalah studi tentang bagaimana individu, kelompok, dan organisasi memilih, membeli, menggunakan, dan bagaimana barang, jasa, ide, atau pengalaman untuk memuaskan kebutuhan dan keinginan mereka. 
Perilaku konsumen terpusat pada cara individu mengambil keputusan untuk memanfaatkan sumber daya yang tersedia seperti waktu, uang, usaha, guna membeli barang yang berhubungan dengan konsumsi. Zeithaml et. al. (2009:18) menyatakan perilaku Konsumen adalah mempelajari bagaimana individu, kelompok, dan organisasi memilih, membeli, memakai, serta memanfaatkan barang, jasa, gagasan, atau pengalaman dalam rangka memuaskan kebutuhan dan hasrat mereka.

\section{Keputusan Pembelian}

keputusan dalam pembelian didefinisikan sebagai suatu pemilihan tindakan dari dua atau lebih pilihan altematif. Bila seseorang dihadapkan pada dua pilihan, yaitu membeli atau tidak membeli dan kemudian dia memilih membeli maka dia berada dalam posisi membuat keputusan. Bila ditinjau dari altematif yang harus dicari, sebetulnya dalam proses pengambilan keputusan, konsumen harus melakukan pemecahan masalah. Masalah timbul dari kebutuhan yang dirasakan dan keinginannya untuk memenuhi kebutuhan itu dengan mengkonsumsi produk atau jasa yang sesuai (Kadir, 2011:15; Maharani dan Darma, 2018).

Menurut Kotler \& Amstrong (2009:179), proses keputusan pembelian terdiri dari lima tahap: pengenalan kebutuhan, pencarian informasi, evaluasi alternatif, keputusan pembelian, dan perilaku pasca pembelian. Proses pembelian dimulai jauh sebelum pembelian sesungguhnya dan berlanjut dalam waktu yang lama setelah pembelian. Pemasar harus memusatkan perhatian pada keseluruhan proses pembelian dan bukan hanya pada keputusan pembelian.

\section{Gambar 2.1}

Proses Keputusan Pembelian

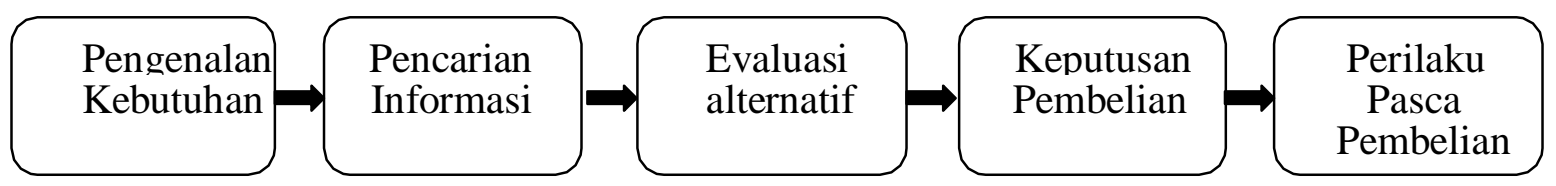

Sumber : Kotler \& Amstrong (2009:179)

\section{Pengaruh Green Marketing Terhadap Perilaku Konsumen}

Azhar (2014:5) mendefenisikan penilaian yang menyeluruh konsumen terhadap seluruh manfaat yang diterima dan apa yang dikorbankan berdasarkan pada hasrat mengenai lingkungan harapan adanya berkelanjutan, segala kebutuhan "hijau". selain itu mengacu pada 
defenisi Azhar (2014:5) dimana green trust adalah sebagai sebuah kehendak untuk bergantung pada sebuah produk jasa, merek atas dasar keyakinan atau harapan yang dihasilkan dari kredibilitas, perbuatan baik, kecakapan tentang kinerja lingkungan. Untuk itu dalam melakukan strategi green marketing sangat penting menimbulkan kepercayaan konsumen karena konsumen akan bergantung pada suatu produk jika harapannya terhadap kualitas, kehandalan serta kebaikan produk terpenuhi dan sesuai dengan yang diinginkan.

Berdasarkan Pengaruh Green Marketing Terhadap Perilaku Konsumen dapat dirumuskan hipotesis seperti berikut ini :

Hipotesis 1 (H1): Semakin baik green marketing maka semakin baik peilaku konsumen.

\section{Pengaruh Quality Brand Berpengaruh Terhadap Perilaku Konsumen}

Penelitian yang dilakukan oleh Maria Margaretha (2016:73) dengan judul Analisis Atribut Produk terhadap Perilaku Pembelian sepatu merk Nike. Dengan hasil penelitian yang telah ada menyatakan bahwa quality brand merupakan variabel yang paling berpengaruh terhadap perilaku pembelian konsumen sepatu olahraga Nike.

Berdasarkan Pengaruh Quality Brand Terhadap Perilaku Kosumen dapat dirumuskan hipotesis seperti berikut ini.

Hipotesis 2 (H2): Semakin baik Quality brand maka semakin meningkat perilaku konsumen.

\section{Pengaruh Perilaku Konsumen Terhadap Keputusan Pembelian}

Zubaidah dan Sahral Hidayat (2017: 42) dengan judul penelitian faktor-faktor yang mempengaruhi perilaku konsumen dalam keputusan pembelian sepatu merek nike di kota Medan. Menunjukan bahwa faktor budaya, sosial, pribadi, dan psikologis mempengaruhi keputusan konsumen teladan barat dalam memilih sepatu merek nike.

Berdasarkan telaah pustaka dan hasil penelitian terdahulu tersebut di atas, maka dapat dibuat hipotesis seperti berikut ini.

Hipotesis 3 (H3) : Perilaku konsumen berpengaruh positif dan signifikan terhadap keputusan pembelian. 


\section{Pengaruh Green Marketing Terhadap Keputusan Pembelian}

Hasil penelitian ini sesuai dengan penelitian Toni hidayat (2013) dengan judul penelitian pengaruh strategi green marketing terhadap keputusan membeli pensil tulis dan pensil warna faber castell pada masyarakat medan dengan hasil penelitian menunjukan bahwa produk hijau, harga, distribusi dan promosi berpengaruh positif dan signifikan terhadap keputusan pembelian.

Berdasarkan telaah pustaka dan hasil penelitian terdahulu tersebut di atas, dapat diajukan hipotesis dalam penelitian ini adalah

Hipotesis 4 (H4): Green marketing berpengaruh positif dan signifikan terhadap keputusan pembelian.

\section{Pengaruh Quality Brand Berpengaruh Terhadap Keputusan Pembelian}

Penelitian yang dilakukan Setiaji dalam Habibah dan Sumiati, (2016) menunjukkan hasil yang serupa yaitu variabel Quality brand berpengaruh terhadap keputusan pembelian Honda MegaPro di Sidoarjo sebesar 51,1\%. Keputusan pembelian yang di gambarkan sebagai proses yang terjadi pada konsumen ketika ia memutuskan membeli, apa yang dibeli, di mana dan bagaimana membelinya. Setiap pembelian konsumen tercipta karena adanya need (kebutuhan keperluan) atau wants (keinginan) atau campuran keduanya.

Berdasarkan telaah pustaka dan hasil penelitian terdahulu tersebut di atas, dapat diajukan hipotesis dalam penelitian ini adalah

Hipotesis 5 (H5): Quality brand berpengaruh positif dan signifikan terhadap keputusan pembelian. 


\section{Kerangka Konseptual}

Green Marketing dan Quality Brand Sebagai Prediktor Perilaku Konsumen Dan Dampaknya Terhadap Keputusan Pembelian Produk Nike

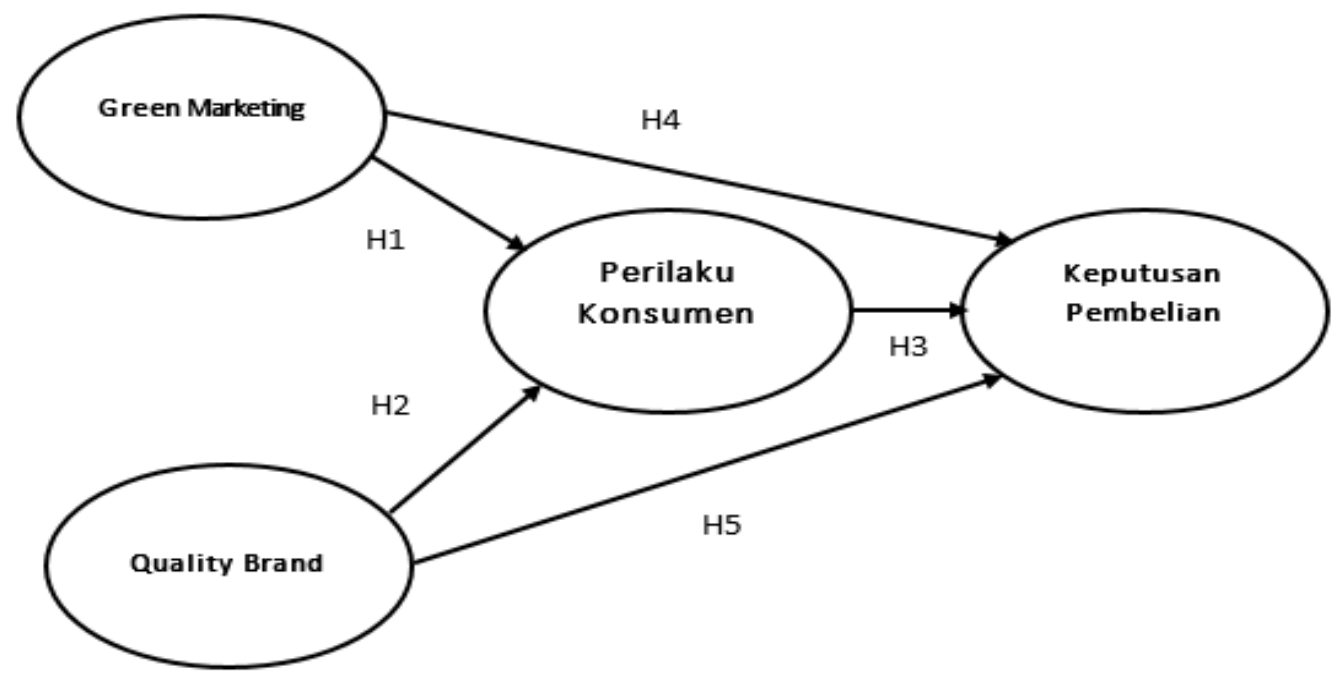

Gambar 2.2 Kerangka Pemikiran

\section{METODE PENELITIAN}

Penelitian ini dilakukan di Nike Store Denpasar yang beralamat di Jalan Teuku Umar No. 91 Denpasar- Bali. Adapun alasan melakukan penelitian di lokasi ini adalah agar dapat membantu memberikan suatu masukan dan pertimbangan bagi pemimpin perusahaan untuk mengetahui pengaruh Green Marketing dan Quality Brand Sebagai Prediktor Perilaku Konsumen Dan Dampaknya Terhadap Keputusan Pembelian Produk Nike Di Kota Denpasar. Teknik pengumpulan data menggunakan kuesioner kepada 140 orang pengguna dan pembeli sepatu Nike yang dipilih sebagai sampel. Data dianalisis dengan Structural Equation Modelling (SEM) dengan program AMOS 22.

\section{PEMBAHASAN}

\section{Hasil Penelitian}

Proses pengujian data telah dilakukan sesuai dengan prosedur yang umum berlaku. Analisis validitas, reliabilitas, dan normalitas data, seluruhnya telah memenuhi syarat. Untuk selanjutnya 
dilakukan pengolahan data hasil pengolahan Structural Equation Modelling (SEM) seperti gambar berikut ini.

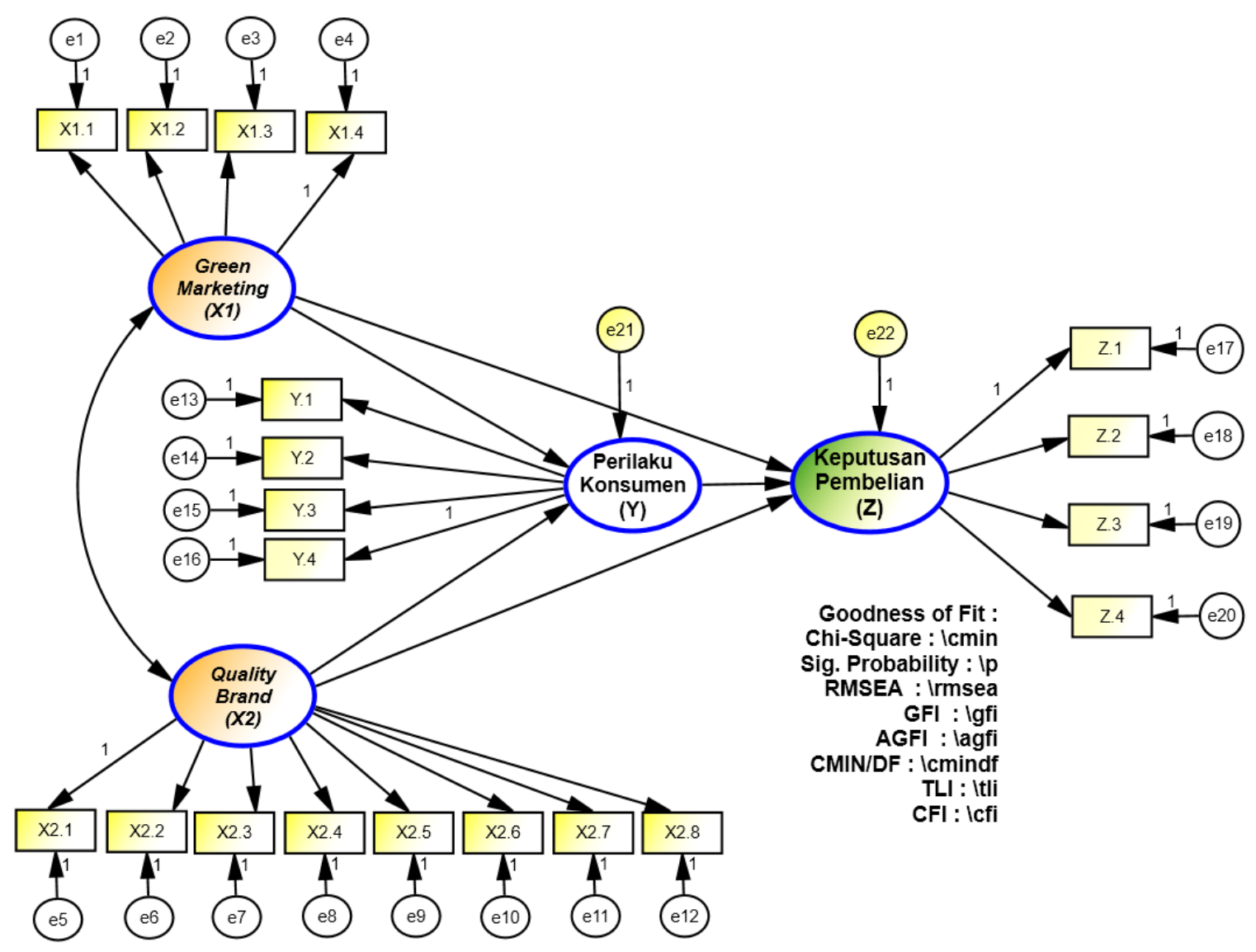

Gambar 4.1

Green Marketing, Quality Brand, Perilaku Konsumen, dan Keputusan Pembelian 
Tabel 4.1

\section{Regression Weights}

\begin{tabular}{|c|c|c|c|c|c|c|c|c|}
\hline & & & Estimate & $\begin{array}{r}\text { Standarized } \\
\text { Estimate }\end{array}$ & S.E. & C.R. & $\mathrm{P}$ & Label \\
\hline Z.1 & $<---$ & $\mathrm{Z}$ & 1.000 & .722 & & & & Valid \\
\hline Y.4 & $<---$ & $\mathrm{Y}$ & 1.000 & .871 & & & & Valid \\
\hline Y.3 & $<--$ & $\mathrm{Y}$ & .776 & .856 & .056 & 13.972 & $* * *$ & Valid \\
\hline Y.2 & $<--$ & $\mathrm{Y}$ & 1.003 & .865 & .071 & 14.194 & $* * *$ & Valid \\
\hline Y.1 & $<--$ & $\mathrm{Y}$ & 1.287 & .972 & .069 & 18.587 & $* * *$ & Valid \\
\hline $\mathrm{X} 2.1$ & $<--$ & $\mathrm{X} 2$ & 1.000 & .500 & & & & Valid \\
\hline $\mathrm{X} 2.2$ & $<---$ & $\mathrm{X} 2$ & .892 & .400 & .229 & 3.892 & $* * *$ & Valid \\
\hline $\mathrm{X} 2.3$ & $<---$ & $\mathrm{X} 2$ & .959 & .378 & .259 & 3.702 & $* * *$ & Valid \\
\hline $\mathrm{X} 2.4$ & $<--$ & $\mathrm{X} 2$ & .973 & .454 & .228 & 4.275 & $* * *$ & Valid \\
\hline $\mathrm{X} 2.5$ & $<---$ & $\mathrm{X} 2$ & 1.456 & .586 & .300 & 4.852 & $* * *$ & Valid \\
\hline Z.2 & $<---$ & $\mathrm{Z}$ & .965 & .723 & .112 & 8.613 & $* * *$ & Valid \\
\hline Z.3 & $<--$ & $\mathrm{Z}$ & .861 & .595 & .123 & 7.007 & $* * *$ & Valid \\
\hline $\mathrm{X} 1.4$ & $<---$ & $\mathrm{X} 1$ & 1.000 & .840 & & & & Valid \\
\hline $\mathrm{X} 1.3$ & $<--$ & $\mathrm{X} 1$ & .719 & .720 & .077 & 9.301 & $* * *$ & Valid \\
\hline $\mathrm{X} 1.2$ & $<---$ & $\mathrm{X} 1$ & .969 & .850 & .086 & 11.288 & $* * *$ & Valid \\
\hline $\mathrm{X} 1.1$ & $<---$ & $\mathrm{X} 1$ & .823 & .800 & .075 & 10.924 & $* * *$ & Valid \\
\hline $\mathrm{X} 2.6$ & $<---$ & $\mathrm{X} 2$ & 1.735 & .704 & .332 & 5.222 & $* * *$ & Valid \\
\hline $\mathrm{X} 2.7$ & $<---$ & $\mathrm{X} 2$ & 1.666 & .716 & .319 & 5.213 & $* * *$ & Valid \\
\hline $\mathrm{X} 2.8$ & $<---$ & $\mathrm{X} 2$ & 2.020 & .806 & .359 & 5.626 & $* * *$ & Valid \\
\hline $\mathrm{Z} .4$ & $<---$ & $\mathrm{Z}$ & 1.190 & .926 & .111 & 10.715 & $* * *$ & Valid \\
\hline
\end{tabular}

Dari tabel di atas, dapat dilihat bahwa tidak ada indikator yang memiliki standardized estimate(regression weight) berupa loading factor atau lamda $(\lambda)<0,5$. Semua indikator memiliki nilai kritis C.R $>$ 2,00 dan probability < 0,05 serta memiliki probabilitas lebih kecil dari 0,05 (***). Dengan demikian dapat dikatakan bahwa semua indikator adalah valid membentuk variabel laten.

Tabel 4.2

\section{Evaluasi Goodness of Fit}

\begin{tabular}{|c|c|c|c|}
\hline $\begin{array}{c}\text { Goodness of Fit } \\
\text { Indeks }\end{array}$ & Cut-off Value & Hasil Analisis & Evaluasi Model \\
\hline Chi-Square $\left(\chi^{2}\right)$ & Diharapkan kecil & 622,862 & Kurang Baik \\
\hline Probability & $\geq 0,05$ & 0,000 & Kurang Baik \\
\hline RMSEA & $\leq 0,08$ & 0,142 & Kurang Baik \\
\hline GFI & $\geq 0,90$ & 0,665 & Kurang Baik \\
\hline AGFI & $\geq 0,90$ & 0,571 & Kurang Baik \\
\hline CMIN/DF & $\leq 2,00$ & 3,798 & Kurang Baik \\
\hline TLI & $\geq 0,95$ & 0,746 & Kurang Baik \\
\hline CFI & $\geq 0,95$ & 0,781 & Kurang Baik \\
\hline
\end{tabular}

Memperhatikan nilai cut-of-value dan goodness of fit hasil model pada Tabel 4.2 di atas, dari delapan kriteria yang dipakai beluam ada memenuhi syarat goodness of fit, sehingga perlu dilakukan modifikasi model. 
Tabel 4.3

Green Marketing, Quality Brand, Perilaku Konsumen, dan Keputusan Pembelian Regression Weights: (Group number 1 - Default model)

\begin{tabular}{|lll|r|r|r|r|r|l|}
\hline & & & Estimate & $\begin{array}{r}\text { Standarized } \\
\text { Estimate }\end{array}$ & S.E. & C.R. & P & Ket \\
\hline Y & $<---$ & X1 & .183 & .209 & .079 & 2.315 & .021 & Signifikan \\
\hline Y & $<---$ & X2 & 1.218 & .588 & .270 & 4.516 & $* * *$ & Signifikan \\
\hline Z & $<---$ & Y & .550 & .633 & .073 & 7.581 & $* * *$ & Signifikan \\
\hline Z & $<---$ & X2 & .704 & .391 & .183 & 3.838 & $* * *$ & Signifikan \\
\hline Z & $<---$ & X1 & .057 & .075 & .039 & 1.453 & .146 & $\begin{array}{c}\text { Tidak } \\
\text { Signifikan }\end{array}$ \\
\hline
\end{tabular}

Dari tabel 4.3 di atas dapat dilihat bahwa ada satu nilai $\mathrm{CR}>2,000$ dan probability $<0,05$, ini berarti ada satu pengaruh variabel eksogen terhadap variabel endogen yang tidak signifikan.

Analisis Model Pengukuran Determinasi

Tabel 4.4 Squared Multiple Correlations

\begin{tabular}{|c|c|}
\hline & Estimate \\
\hline $\mathrm{Y}$ & .517 \\
\hline $\mathrm{Z}$ & .984 \\
\hline
\end{tabular}

Dari keseluruhan analisis di atas dapat disimpulkan semua indikator untuk Green Marketing $\left(\mathrm{X}_{1}\right)$, Quality Brand $\left(\mathrm{X}_{2}\right)$, Perilaku Konsumen (Y) dan Keputusan Pembelian (Z) adalah Valid/signifikan. Bila dilihat dari Model persamaan struktural di atas menunjukkan Regression Weight $(\gamma)$ terdapat empat variabel yang pengaruhnya positip signifikan dan satu pengaruh positip yang tidak signifikan. Dari hasil Evaluasi Goodness of Fit belum ada kriteria yang memenuhi Goodness of Fit. Dengan demikian maka model tersebut belum dapat dinyatakan sebagai model yang baik (belum memenuhi Goodness of fit) dan dipandang perlu diadakan modifikasi model untuk dapat meningkatkan kecocokan model (Goodness of fit) (Solimun, 2004:71 dan Solimun, 2006:19).

Untuk meningkatkan nilai Goodness of fit dapat dilakukan dengan tidak mengikut sertakan indikator yang memiliki koefisien Standarized Regression Weight antara indikator $\lambda$ (loading factor) kecil ataupun mengkorelasikan beberapa indikator yang memiliki nilai Modifikasi Indeks (M.I.) yang besar (Ferdinand, 2006:190). 


\section{Modifikasi}

Pada Modifikasi ini dilakukan dengan mengkorelasikan beberapa error yang memiliki koefesien Modifikasi Indeks (M.I) besar. Untuk keperluan tersebut maka berikut ini ditampikan Tabel 4.5 yang memuat koefisien Modifikasi Dengan menghubungkan beberapa error diatas maka dapa dihasilkan model modifikasi sebagai berikut.

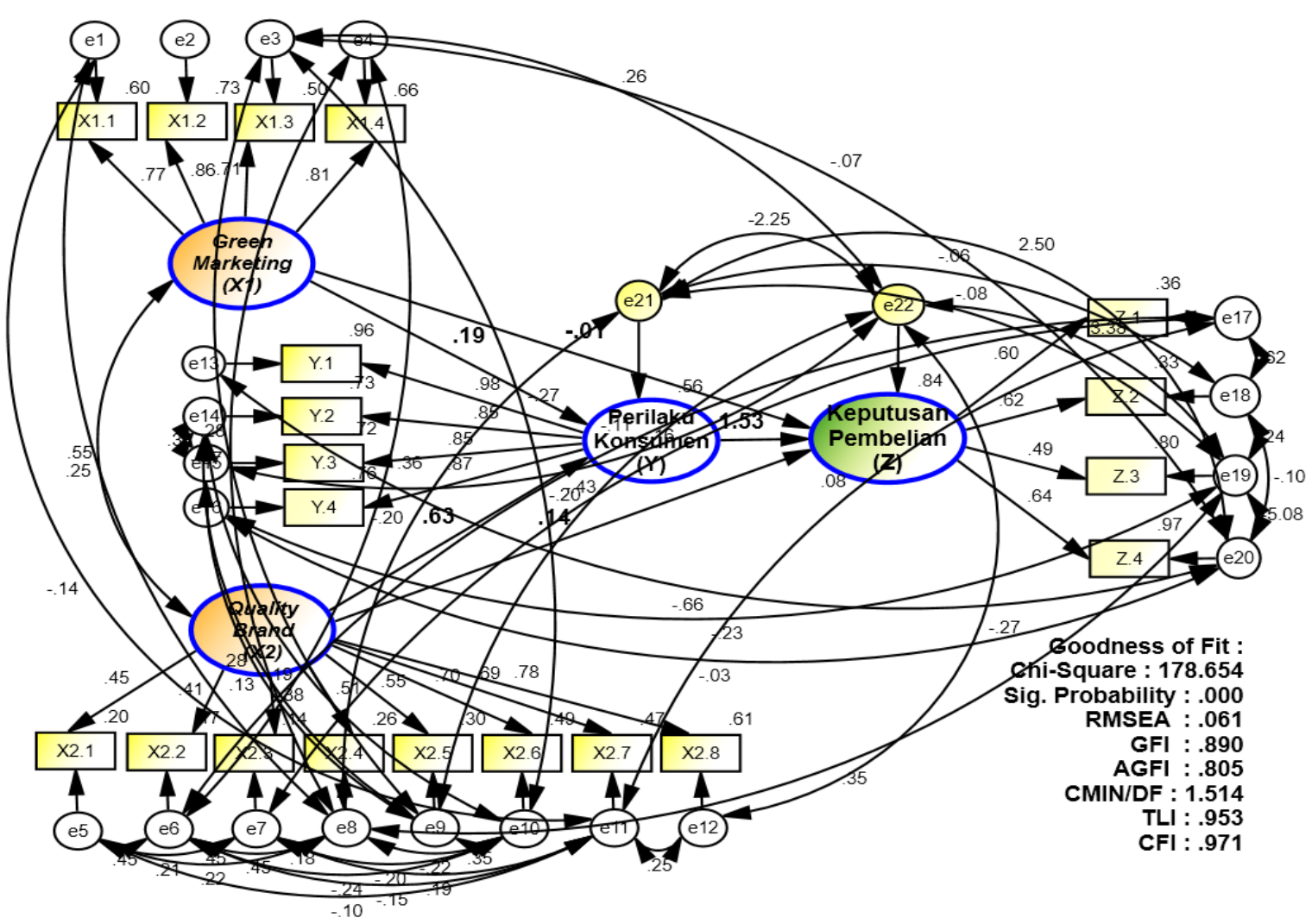

Gambar 4.2

\section{Hasil Modifikasi Model}

Dari hasil modifikasi model dengan mengkorelasikan beberapa error indikator yang memiliki Modification Index (M.I.) > 4,000 maka dapat dilakukan perbandingan Goodness of Fit antara model modifikasi utama dengan model hasil modifikasi. Perbandingan yang dilakukan meliputi : besarnya koefisien Goodness of Fit, koefisien Regression Weight antar variabel endogen dengan eksogen, dan Square Multiple Correlation sebagai cerminan koefisien determinasi 
Tabel 4.5

Perbandingan Model Utama dengan Hasil Modifikasi

\begin{tabular}{|c|c|c|c|c|}
\hline Goodness of Fit Index & $\begin{array}{l}\text { Cut-of } \\
\text { Value }\end{array}$ & Model Utama & $\begin{array}{c}\text { Model } \\
\text { Modifikasi }\end{array}$ & Keterangan \\
\hline Chi-Square $\left(\chi^{2}\right)$ & $\begin{array}{c}\text { Diharapkan } \\
\text { kecil }\end{array}$ & 622,862 & 178,654 & Lebih baik \\
\hline Probability & $\geq 0,05$ & 0,000 & 0,000 & Tetap \\
\hline RMSEA & $\leq 0,08$ & 0,142 & $\left.0,061^{*}\right)$ & Lebih baik \\
\hline GFI & $\geq 0,90$ & 0,665 & $0,890^{+)}$ & Lebih baik \\
\hline AGFI & $\geq 0,90$ & 0,571 & $0,805^{+)}$ & Lebih baik \\
\hline CMIN/DF & $\leq 2,00$ & 3,798 & $\left.1,514^{*}\right)$ & Lebih baik \\
\hline TLI & $\geq 0,95$ & 0,746 & $\left.0,953^{*}\right)$ & Lebih baik \\
\hline CFI & $\geq 0,95$ & 0,781 & $\left.0,971^{*}\right)$ & Lebih baik \\
\hline \multicolumn{2}{|l|}{$\mathbf{Y} \leftarrow \mathbf{X 1}\left(\gamma_{\mathrm{x} 1 \mathrm{Y}}\right)$} & $0,209^{++)}$ & $0,189^{++)}$ & Lebih jelek \\
\hline \multicolumn{2}{|l|}{$\mathbf{Y} \leftarrow \mathbf{X} \mathbf{2}\left(\gamma_{\mathrm{X} 2 \mathrm{Y}}\right)$} & $0,588^{++)}$ & $0,630^{++)}$ & Lebih baik \\
\hline \multicolumn{2}{|l|}{$\mathbf{Z} \leftarrow \mathbf{Y}\left(\gamma_{\mathrm{YZ}}\right)$} & $0,633^{++)}$ & $1,525^{++)}$ & Lebih baik \\
\hline \multicolumn{2}{|l|}{$\mathbf{Z \leftarrow X 2} \quad\left(\gamma_{\mathrm{X} 2 Z}\right)$} & $0,391^{++)}$ & $0,140^{--)}$ & Lebih jelek \\
\hline \multicolumn{2}{|c|}{$\mathbf{Z} \leftarrow \mathbf{X 1}\left(\gamma_{\mathrm{X} 1 \mathrm{Z}}\right)$} & $0,075^{--)}$ & $-0,005^{--)}$ & Lebih jelek \\
\hline \multirow{2}{*}{\multicolumn{2}{|c|}{$\begin{array}{l}\text { Square Multiple Perilaku Konsumen (Y) } \\
\text { Square Multiple Keputusan Pembelian (Z) }\end{array}$}} & 0,517 & 0,565 & Lebih baik \\
\hline & & 0,984 & 0,841 & Lebih jelek \\
\hline
\end{tabular}

*) Memenuhi Goodness of fit

$++)$ Signifikan

+) Marginal

--) Tidak Signifikan

Bila dilihat dari Goodness offit, terlihat model hasil modifikasi menunjukkan perbaikan pada tujuh indikator dari delapan indikator yang ada. Model utama yang semula tidak ada indikator memenuhi Goodness of fit, menjadi empat buah indikator yang memenuhi syarat yaitu Relatitive Chi-square ( $\left.\chi^{2} / \mathrm{df}\right)$, RMSEA, TLI, dan CFI. Bila dilihat dari Regresion Weight variabel eksogen terhadap variabel endogen ternyata pada modifikasi model, terdapat peningkatan pada dua koefisen regresi (Standarized Regresion Weight) dan tiga lainnya mengalami penurunan. Bila dilihat dari Square Multiple Correlation, terlihat satu mengalami peningkatan, dan satu mengalami penurunan

Dari analisis diatas, dapat dinyatakan bahwa melakukan modifikasi model telah dapat meningkatkan kesesuaian model (Goodness of fit). Berhubung telah ada empat (lebih dari satu buah indikator yang memenuhi syarat goodness of fit dan satu buah marginal, maka model telah dipandang bagus (good of fit). Hal ini sesuai dengan Solimun, (2002:80) dan Solimun (2004:71). Dengan demikian dipandang tidak perlu lagi mengadakan modifikasi lebih lanjut.

\section{Pengaruh Green Marketing Terhadap Perilaku Konsumen}

Diterimanya hipotesis pertama yang menyatakan green marketing berpengaruh terhadap perilaku konsumen sejalan dengan pendapat Haryadi (2009:9) menyatakan bahwa 
strategi perusahaan yang menggunakan green marketing sebagai strategi potensial sebagai strategi bisnis yang dapat menjadi poros strategi bisnis yang sukses dan keunggulan bersaing. Selain itu pendapat Azhar (2014:5) mendefenisikan penilaian yang menyeluruh konsumen terhadap seluruh manfaat yang diterima dan apa yang dikorbankan berdasarkan pada hasrat mengenai lingkungan harapan adanya berkelanjutan, segala kebutuhan "hijau". selain itu mengacu pada defenisi Azhar (2014:5) dimana green trust adalah sebagai sebuah kehendak untuk bergantung pada sebuah produk jasa, merek atas dasar keyakinan atau harapan yang dihasilkan dari kredibilitas, perbuatan baik, kecakapan tentang kinerja lingkungan. Untuk itu dalam melakukan strategi green marketing sangat penting menimbulkan kepercayaan konsumen karena konsumen akan bergantung pada suatu produk jika harapannya terhadap kualitas, kehandalan serta kebaikan produk terpenuhi dan sesuai dengan yang diinginkan.

\section{Pengaruh Quality Brand Berpengaruh Terhadap Perilaku konsumen}

Diterimanya hipotesis kedua yang menyatakan quality brand berpengaruh terhadap perilaku konsumen sejalan dengan pendapat Kotler dan Armstrong (2012: 254) yang menyatakan quality brand merupakan kemampuan suatu produk untuk melakukan fungsifungsinya dalam memenuhi kebutuhan konsumen. Menurut Schiffman dan Kanuk (2010: 23), perilaku dijelaskan sebagai tingkah laku dari para konsumen untuk memperoleh, membeli, memakai, mengevaluasi, dan menghabiskan produk atau jasa yang mereka harapkan akan memuaskan kebutuhan mereka. Selain itu hasil penelitian ini sejalan dengan hasil penelitian yang dilakukan oleh Margaretha (2016:73) yang menemukan quality brand merupakan variabel yang paling berpengaruh terhadap perilaku pembelian konsumen sepatu olahraga Nike.

\section{Pengaruh Perilaku Konsumen Terhadap Keputusan Pembelian}

Diterimanya hipotesis ketiga yang menyatakan perilaku konsumen berpengaruh terhadap keputusan pembelian sejalan dengan pendapat Kotler dan Amstrong (2011), yang menyatakan beberapa perilaku yang mempengaruhi perilaku konsumen, diantaranya yaitu faktor psikologis. Adapun macam dari faktor psikologis antara lain, yaitu motivasi, presepsi, pembelajaan, dan keyakinan atau kepercaaan. Hal serupa diungkapkan dalam penelitian yang dilakukan oleh Benito (2011:21) menyatakan dalam penelitiannya bahwa kepercayaan, 
kemudahaan dan kualitas informasi berpengaruh positif dan signifikan terhadap keputusan pembelian.

Hasil penelitian ini sejalan pula dengan hasil penelitian yang dilakukan oleh Didin dkk. (2013) menemukan bahwa Perilaku Konsumen yang terdiri dari variabel budaya, sosial, pribadi dan psikologis secara bersama-sama memiliki pengaruh terhadap Keputusan Pembelian.

\section{Pengaruh Green Marketing Terhadap Keputusan Pembelian}

Ditolaknya hipotesis keempat yang menyatakan green marketing berpengaruh terhadap keputusan pembelian sejalan dengan hasil penelitian yang dilakukan oleh Manongko (2011:58) yang menemukan bahwa green marketing kurang mampu memberikan pengaruh yang signifikan terhadap keputusan pembelian.

\section{Pengaruh Quality Brand Berpengaruh Terhadap Keputusan Pembelian}

Diterimanya hipotesis kelima yang menyatakan quality brand berpengaruh terhadap keputusan pembelian sejalan dengan pendapat Ariyoto (2001:92) yang menyatakan kualitas adalah totalitas bentuk dan karakteristik barang yang menunjukkan kemampuannya untuk memuaskan kebutuhan dan keinginan dari konsumen. Selain itu hasil penelitian ini sejalan pula dengan hasil penelitian yang dilakukan Purwati dan Rohmawati (2012) menunjukkan bahwa Quality brand memiliki korelasi yang kuat dengan pengambilan keputusan pembelian, sehingga dengan perusahaan memuculkan Quality brand yang baik maka konsumen akan cenderung melakukan pembelian terhadap produk tersebut seperti produk nike.

\section{PENUTUP}

1 Green marketing berpengaruh positif dan signifikan terhadap perilaku konsumen. Dengan demikian hipotesis pertama yang menyatakan green marketing berpengaruh terhadap perilaku konsumen adalah teruji kebenarannya.

2 Quality brand berpengaruh positif dan signifikan terhadap perilaku konsumen. Dengan demikian hipotesis kedua yang menyatakan quality brand berpengaruh terhadap perilaku konsumen adalah teruji kebenarannya. 
3 Perilaku konsumen berpengaruh positif dan signifikan terhadap keputusan pembelian. Dengan demikian hipotesis ketiga yang menyatakan perilaku konsumen berpengaruh terhadap keputusan pembelian adalah teruji kebenarannya.

4 Green marketing memiliki pengaruh positif yang tidak signifikan terhadap keputusan pembelian. Dengan demikian hipoteisis keempat yang menyatakan green marketing berpengaruh terhadap keputusan pembelian adalah tidak teruji kebenarannya.

5 Quality brand berpengaruh positif dan signifikan terhadap keputusan pembelian. Dengan demikian hipoteisis kelima yang menyatakan qality brand berpengaruh terhadap keputusan pembelian adalah teruji keberannya adalah teruji keberannya.

6 Perilaku konsumen mampu memediasi pengaruh green marketing terhadap keputusan pembelian. Dengan demikian hipotesis keenam yang menyatakan perilaku konsumen memediasi pengaruh green marketing terhadap keputusan pembelian adalah teruji kebenarannya.

7 Perilaku konsumen mampu memediasi pengaruh quality brand terhadap keputusan pembelian. Dengan demikian hipotesis ketujuh yang menyatakan perilaku konsumen memediasi pengaruh quality brand terhadap keputusan pembelian adalah teruji kebenarannya. 


\section{DAFTAR PUSTAKA}

Abdul, K. (2011). Faktor-Faktor yang Berpengaruh Terhadap Ketepatan Waktu Pelaporan Keuangan Studi Empiris Pada Perusahaan Manufaktur di Bursa Efek Indonesia.

Almasdi, J.S. (2012). Aspek Sikap Mental Dalam Manajemen Sumber Daya Manusia. Jakarta: Syiar Media.

Ariani, D.W. (2009). Manajement Operasi Jasa. Yogyakarta: Graha Ilmu.

Ariyoto, K. (2001). Prinsip-prinsip manajemen operasi. Jakarta: Salemba empat.

Arsyad, A. (2014). Media Pembelajaran. Jakarta: PT. Raja Grafindo Persada.

Balawera, A. (2013). Green Marketing dan Corporate Social Responsibility Pengaruhnya terhadap keputusan pembelian konsumen melalui minat membeli produk organic di FreshMart Kota Manado, Jurnal EMBA, 1 (4): 211-220.

Barnes, J. (2003). Secret of Costomer Relationship Manajemen, Rahasia Hubungan Pelanggan. Yogyakarta: Andi.

Benito, A. (2011). Analisis Pengaruh Kepercayaan, Kemudahan Dan Kualitas Informasi Terhadap Keputusan Pembelian Secara Online Di Situs Kaskus, Journal of marketing Research, 3: 3-7.

Byrne, M. (2003). Understanding Consumer Preferences Across Environmental Marketing Mix Variations. OIKOS University of Newcastle.

Bukhari. (2011). Green Marketing and its impact on consumer behavior. 3.

Candra, Y. (2012). Pengaruh Bauran Pemasaran dan Keterlibatan Keluarga Terhadap Keputusan Pembelian Leasing Sepeda Motor Suzuki di Kabupaten Pesisir Selatan, Jurnal Manajemen dan Kewirausahaan, 3 (1): 1 -35.

Chan, Yu-Shan. (2010). The Drivers of Green Brand Equity: Green Brand Image, Green Statisfaction, and Green Trust, Journal of Business Ethics, 93: 307-319.

Chan, Yu-Shan, Ching-Hsun Chang. (2012). Greenwash and Green Trust: The Mediation Effects of Green Consumer Confusion and Green Perceived Risk. Springer Scince + Business Media B.V, journal of marketing management, 25 (7): 489-500.

Costabile. (2014). Jurnal Manajemen dan Kewirausahaan, 6 (2).

Darma, G.S. (2018). Seuntai Pesan, Menjawab Zaman. Indonesia: Pustaka Larasan Press.

Ginantra, K.G., Lestari, N.P.N.E., Gorda, A.A.N.E.S., and Darma, G.S. (2017). Effects of Promotion, Product Quality, Brand Image and Price on Customer Satisfaction and 
Brand Switching Decision, International Journal of Management and Economics Invention, 3 (12): 1514-1523.

Giovanna, N., and Darma, G.S. (2019). Scanlated vs. Physical Japanese Comic Manga, International Journal of Innovative Science and Research Technology, 4 (1): 630-636.

Handika, M.R., Maradona, A.F., and Darma, G.S. (2018). Strategi Pemasaran Bisnis Kuliner Menggunakan Influencer Melalui Media Sosial, Jurnal Manajemen \& Bisnis, 15 (2): 188-199.

Hanum, Z., Sahral Hidayat. (2017). Faktor - Faktor Yang Mempengaruhi Perilaku Konsumen Dalam Keputusan Pembelian Sepatu Merek Nike Di Kota Medan, Jurnal Manajemen, $6(1)$.

Hidayat, T. (2013). Pengaruh Strategi Green Marketing Terhadap Keputusan Membeli Pensil Tulis Dan Pensil Warna Faber Castell Pada Masyarakat Medan. Tesis Mahasiswa Universitas Sumatra Utara, Jurnal Ekonomi Manajemen, 1: 23.

Kusnadi, D.S., and Darma, G.S. (2018). Menakar Implementasi Green Marketing Pada Usaha Kecil Menengah, Jurnal Manajemen \& Bisnis, 15 (1): 1-18.

Maharani, I.G.A.P.D., and Darma, G.S. (2018). Consumer Purchasing Behavior Analysis on Impulse Buying, Jurnal Manajemen \& Bisnis, 15 (3): 16-37.

Manongko, A.A.CH. (2011). Green Marketing dan Pengaruhnya Terhadap Keputusan Pembelian Melalui Minat Membeli Produk Organik (Studi Pada Pelanggan Produk Organik di Koto. Manado).

Meliana., Sulistiono., dan Budi. (2003). Pengaruh Kualitas Pelayanan dan Kepercayaan Konsumen Terhadap Keputusan Pembelian (STUDI KASUS PADA GIANT HYPERMARKET), Jurnal Ilmiah Manajemen, (3).

Morgan, R.M., dan shelby D. Hunt. (2004). The commitment-trust theory of relationship marketing, Journal of Marketing, 58: 20-38.

Ottman, J.A., et al. (2006). Green Marketing Myopia: Ways to Improve ConsumerAppeal for Environmentally Preferable Products, Heldref Publications Environment, 48 (5): 22 36.

Putra, I.G.N.A.P., and Darma, G.S. (2019). Is Bitcoin Accepted in Indonesia, International Journal of Innovative Science and Research Technology, 4 (2): 424-430. 
Putripeni, M.P., Suharyono., Andriani Kusumawati. (2014). Pengaruh Green Marketing Terhadap Citra Merek dan Keputusan Pembelian (Studi pada Konsumen The Body Shop Mall Olympic Garden Malang), Jurnal Administrasi Bisnis, 10 (1): 1-10.

Pappers, D., dan Rongers. (2004). Managing costumer relationships: A Strategic Framework. USA: Jhon wiley and sons, inc.

Purwati dan Rohmawati. (2012). Pengaruh Harga dan Kualitas Produk Terhadap Kepututsan Pembelian Motor Honda Matic Beat (Studi Kasus Pada PT. Nusantara Solar Sakti), Jurnal Ekonomi Dan Informasi Akuntansi (Jenius), 2 (3).

Ratminto dan Atik Septi Winarsih. (2005). Manajemen Pelayanan.Yogyakarta: Pustaka Belajar

Rina, R. (2011). Peranan Bauran Pemasaran (Marketing Mix) terhadap Peningkatan, 2.

Rusmahadewi, I.A., and Darma, G.S. (2018). Team Engagement and Performance Management (A Study of Banking Industry), Jurnal Manajemen \& Bisnis, 15 (3): 3850.

Setyawati, T., and Darma, G.S. (2018). Efektifkah Experiential Marketing di Sebuah Rumah Sakit ?, Jurnal Manajemen \& Bisnis, 15 (1): 160-175.

Sumaryati, M.M. (2016). Analisis Atribut Produk Terhadap Perilaku Pembelian Konsumen Sepatu Merek Nike, Jurnal Manajemen, 13 (1): 58-75.

Shaputra, R.K. (2013). Penerapan Grenn Marketing pada bisnis produk kosmetik, Jurnal JIBEKA, 7 (3): 47-53.

Sholahudin, R. (2013). Pengaruh Green Marketing Terhadap Keputusan Pembelian Produk Ades Jurusan PIPS Fakultas Keguruan danllmu Pendidikan Universitas Sebelas Maret Tahun 2013. Skripsi. FKIP UNS, 30-55.

Saleh, A.M. (2010). Public Service Communication. Malang: UMM Press.

Santoso, S. (2007). Riset Pemasaran (Konsep dan aplikasi dengan SPSS). Jakarta: PT. Elex Media Komputindo.

Scypa, P. (2006). Lingkungan Pemasaran dan Povedenie Potrebitelskoe/Russian Market. Ekonomi dan Manajemen: Current Issues and Perspective.156-159.

Setiadi, N.J. (2003). Perilaku Konsumen. Jakarta: Kencana.

Schiffman dan Lazar L Kanuk. (2008). Perilaku Konsumen. Edisi Ketujuh.

Solimun. (2002). Structural Equation Modeling LISREL dan Amos, Fakultas MIPA Universitas Brawijaya, Malang. 
Sumarsono. (2003). Pengetahuan Konsumen terhadap Ecolabelling serta Pengaruhnya pada Keputusan Pembelian Produk Ramah Lingkungan, Performance, 15 (1): 70-85.

Sunarto. (2006). Pengantar Manajemen pemasaran. Get. 1. Yogyakarta: Ust Press.

Surjandari, I., dan Susetiana, H. (2009). Analisis Loyalitas Pelanggan.

Syahbandi. (2012). Implementasi Green Marketing Melalui Pendekatan Marketing Mix, Demografi Dan Pengetahuan Terhadap Pilihan Konsumen (Study The Body Shop Pontianak), 3.

Tjiptono, F. (2012). Service Management Mewujudkan Layanan Prima. edisi II. Yogyakarta: C.V ANDI OFFSET.

Tjiptono, F., dan Gregorius Chandra. (2012). Pemasaran Strategik. Yogyakarta.

Wahyuddin, M., dan Ambar Muryati. (2001). Faktor-faktoir yang Mempengaruhi Kepuasan Pelanggan Perusahaan Daerah Air Minum (PDAM) Kabupaten Klaten, Jurnal Manajemen Daya Saing.

Wiandari, I.A.A., and Darma, G.S. (2017). Kepemimpinan, Total Quality Management, Perilaku Produktif Karyawan, Kinerja Karyawan dan Kinerja Perusahaan, Jurnal Manajemen \& Bisnis, 14 (2): 61-78.

Zeithaml, et al. (2009). Service Quality Delivery Through Web Sites: A Critical Review of Extant Knowledge, Journal of the academy of marketing science. 